\title{
A questão da consciência na Psicologia de Wilhelm Wundt
}

\section{The Question of Consciousness in Wilhelm Wundt's Psychology}

\section{Cíntia Fernandes Marcellos*}

Universidade Federal de Juiz de Fora - UFJF, Juiz de Fora, MG, Brasil

\section{Saulo de Freitas Araujo**}

Universidade Federal de Juiz de Fora - UFJF, Juiz de Fora, MG, Brasil

\begin{abstract}
RESUMO
O trabalho apresenta o conceito de consciência de Wilhelm Wundt, formulado na fase madura de sua obra e sustentado por uma definição de Psicologia como ciência da experiência imediata, cujo acesso, para fins científicos, só é possível de forma indireta, mediante o recurso ao método experimental e à observação. A consciência, concebida como um fluxo de processos cuja ocorrência é uma delimitação da totalidade mental, é o objeto por excelência desta psicologia e é estudada em seus aspectos representacional, afetivo e volitivo. O estudo apresenta ainda a consideração dos elementos constituintes da consciência, suas formas compostas e as leis organizadoras de tais associações, concluindo com a discussão acerca da relevância da formulação psicológica wundtiana como exemplo de uma tentativa de estabelecimento da autonomia e coerência da Psicologia.

Palavras-chave: Consciência, Wilhelm Wundt, História da Psicologia.
\end{abstract}

\section{ABSTRACT}

This paper explores Wilhelm Wundt's concept of consciousness in its definitive formulation. It is supported by the definition of psychology as the science of immediate experience, which can only be indirectly accessed through experimental method and observation. Consciousness, conceived as a processual flux whose occurrence delimits the totality of mind, is the primary subject matter of psychology, and it is studied in its representational, affective and volitive aspects. The constitutive elements of consciousness, their composite forms and the organizing laws of such associations are also presented. Finally, the relevance of Wundt's psychological formulation as example of a attempt of the establishment of psychology as an autonomous discipline is discussed.

Keywords: Consciousness, Wilhelm Wundt, History of Psychology. 
A definição do objeto de investigação e do método a ser empregado em seu estudo são dois fatores centrais que configuram a constituição de uma ciência. A consciência, muitas vezes alçada à condição de objeto da psicologia, é alvo de um interesse que percorre grande parte da história da disciplina. Se por um lado isso demonstra a relevância que o conceito adquiriu para explicar, ou ao menos organizar, a diversidade dos fenômenos mentais, por outro, a amplitude semântica que o mesmo encontra em cada teoria torna a tentativa de alcançar um consenso uma tarefa até o momento malograda. Usado por diferentes escolas de pensamento em psicologia, sua definição insuficiente tem atravessado as fronteiras teóricas e persistido ainda hoje, fazendo com que seu poder heurístico seja reduzido e sua aplicação banalizada.

Nesse contexto, a relevância das investigações voltadas para o desenvolvimento histórico e filosófico da psicologia situa-se não em um mero apego passadista, mas sim, como afirma Koch, na necessidade de situar "onde nos encontramos no momento presente, tendo em mente a relação com os objetivos historicamente constituídos pela "nova psicologia" e seus pioneiros" (KOCH, 1980, p. 5). Com o intuito de situar a fundamentação científica deste conceito, estudos atuais acerca da consciência envolvem tanto questionamentos de caráter filosófico (STURM; WUNDERLICH, 2010), como estritamente psicológicos, voltados para um possível compartilhamento de significados (FERRARI; ROBINSON; YASNITSKY, 2010). A partir destes esforços e sob uma perspectiva que considere a análise lógica interna de cada teoria, pode-se pretender fazer avançar um campo de conhecimentos que ainda hoje se apresenta como um quebra-cabeças inarticulado e sem imagem definida.

Ao retomar o conceito de consciência elaborado por Wilhelm Wundt (1832-1920), pretendemos recuperar um programa de pesquisas que foi capaz de organizar a institucionalização da psicologia como área de estudos e pesquisas no século XIX, mantendo-se comprometido com seus pressupostos filosóficos e com o referencial científico de seu tempo. Se em sua época modelos concorrentes estiveram presentes e sua formulação não logrou alcançar o consenso citado, seus cuidados na definição precisa do conceito bem como do método capaz de estudá-lo o tornam merecedor de uma releitura.

A originalidade de seu programa de pesquisas encontra-se no abandono do tratamento metafísico tradicional dado à vida mental e na tentativa de se manter fiel às novas perspectivas apresentadas pelas ciências naturais, especialmente em relação ao método experimental, sem, contudo, comprometer ou reduzir a singularidade e a autonomia da psicologia frente a estes referenciais. Com este intuito, Wundt empreendeu um prolongado diálogo com a tradição filosófica de seu tempo e conduziu dezenas de pesquisas acerca de fenômenos como apercepção, sensação, atenção, sentimentos, 
memória, entre outros (TINKER, 1980), sendo ainda responsável pela fundação, em 1881, de um dos primeiros periódicos dedicados aos estudos sobre a vida mental realizados em psicologia (BRINGMANN; BRINGMANN; UNGERER, 1980).

Atento ao rigor epistemológico e a uma consistente fundamentação filosófica, sua adoção da consciência como objeto de uma psicologia científica referia-se a um recorte da vida mental passível de ser estudado mediante especificações do método experimental e conforme uma concepção acerca da natureza da experiência interna, que realçava suas dimensões afetiva e volitiva. Com isto, distanciouse do associacionismo britânico, do empirismo e do estruturalismo na ênfase dada aos aspectos intelectuais em detrimento dos demais (ARAUJ O, 2007, p. 102-103).

Defendendo que a resposta ao problema do status da psicologia como ciência deveria ser uma tarefa empreendida no âmbito das investigações empíricas, fundamentadas pela lógica e pela teoria do conhecimento e testadas em suas hipóteses, e não pelas possíveis aplicações práticas de seus conhecimentos, suas contribuições não encontraram continuidade na história da psicologia. Tal fato pode ser explicado por diferentes fatores que, em parte, são decorrentes de características da obra de Wundt e, em parte, devem-se a fatores externos, de caráter histórico e político. Dentre os primeiros, podemos citar a amplitude de seu projeto intelectual e a extensão de sua obra, que ainda hoje não conta com traduções confiáveis e uma edição crítica de referência, dificultando assim o acesso dos atuais pesquisadores. Outro aspecto de maior relevância é o distanciamento da tradição intelectual em que sua obra foi gerada, o que tem levado a avaliações imprecisas ou tendenciosas de suas idéias (BLUMENTHAL, 1980). Este fato deve ser considerado, especialmente, quando se tem em mente a migração de suas idéias para outros países, onde elas concorreram ou foram filtradas por distintas tradições de pensamento e culminaram num total abandono ou numa adesão parcial, restrita aos métodos e técnicas aplicados no estudo da nova ciência da mente (TAIANA, 2005).

Embora se reconheçam os esforços empreendidos pela historiografia da psicologia neste momento, os interesses que pautaram tal impulso contribuíram ainda mais para a divulgação parcial e reducionista da obra de Wundt. Com isso, as idéias atribuídas à Wundt foram sendo parcialmente substituídas por outras e sua obra gradativamente abandonada após sua morte (BROZECK, 1980; RIEBER, 2001). A combinação desses fatores contribuiu para que sistema teórico proposto por Wundt não fosse seriamente discutido ou refutado, mas apenas abandonado e substituído, relegando-o ao papel de mero adereço figurativo, pertencente a um passado mudo aos desdobramentos atuais.

Embora este trabalho não pretenda uma confrontação de suas idéias 
com definições contemporâneas, espera-se, contudo, contribuir para a mudança deste cenário de esquecimento através da apresentação pormenorizada de seu conceito de consciência. Trata-se aqui das definições dos processos psicológicos, mediante a apresentação de um quadro geral dos pressupostos filosóficos, relacionado a algumas das idéias centrais de sua psicologia. Com isso, deixaremos de lado a discussão sobre seu projeto psicológico inicial e a apresentação detalhada de seu projeto intelectual mais amplo, de caráter filosófico (cf. WUNDT, 1913; 1920). Para evitarmos os já conhecidos obstáculos ao estudo das obras de Wundt (cf. BLUMENTHAL, 1980; 2001; ARAUJO, 2009a), como os resultantes dos consagrados problemas de interpretação, de seu caráter continental e da escassez de traduções, vamos nos restringir aqui à fase madura de seu pensamento (1889-1920), conforme a classificação de Araujo (2010), recorrendo a algumas de suas obras originais e à bibliografia secundária atualizada.

\section{A definição de psicologia e seus pressupostos centrais}

Antes de alcançarmos o alvo de nosso trabalho, é preciso estabelecer dentro de qual constelação conceitual a definição de consciência wundtiana assume seu significado. O primeiro passo refere-se à própria definição da ciência que com maior centralidade se ocupa dos fenômenos psíquicos, a psicologia.

Entendida como "ciência empírica da experiência imediata" (WUNDT, 1897, p. 6), o objetivo da Psicologia seria investigar a interconexão dos conteúdos dessa experiência, mediante os mesmos recursos das ciências naturais, isto é, a observação e o experimento. Tal definição nos coloca diante de um dos principais pressupostos do pensamento wundtiano, a saber, a noção de experiência imediata. Criticando as concepções substancialistas acerca da vida mental, Wundt defende um monismo segundo o qual a complexidade da experiência humana é entendida como um todo unificado e coerente, podendo ser observada a partir de sua relação com os objetos da experiência ou exclusivamente a partir da referência ao sujeito. Em função desta característica, a experiência poderia ser abordada por dois pontos de vista distintos, porém complementares. Um deles refere-se ao domínio que procura, em suas investigações, abstrair a atividade do sujeito e considerar somente os objetos em sua regularidade espaçotemporal. Por este motivo e por recorrer à formulação conceitual, seria dito mediato ou externo e caracterizaria o tipo de experiência ao qual se dedicam as ciências naturais. O outro tipo de experiência, chamada de imediata ou interna, seria aquele referente ao domínio intuitivo, ou seja, da apreensão direta dos próprios fenômenos subjetivos. A ciência mais geral que adota esta perspectiva seria a psicologia (WUNDT, 1897, p. 1-6).

Para Wundt (1897), enquanto a experiência mediata contaria com a 
regularidade e a constância do objeto, além de certa independência em relação à apreensão subjetiva, garantindo assim a nãointerferência do observador e a possibilidade de manipulação experimental, os fenômenos da experiência interna seriam caracterizados por um caráter ativo e processual:

Esse conceito de processo exclui a atribuição de um caráter objetivo mais ou menos permanente aos conteúdos da experiência psíquica. Fatos psíquicos são ocorrências, não objetos; eles têm lugar no tempo, como toda ocorrência, mas nunca o mesmo lugar num dado ponto do tempo, como eles estavam no momento precedente. (p. 14 - ênfase no original)

É este aspecto que caracteriza o que Wundt chamou de princípio de processualidade ou atualidade da mente (Prinzip der Aktualität), afirmando que o conceito de mente deve referir-se tão somente à realidade imediata de seus próprios processos (1897, p. 314). Em An Introduction to Psychology (1912), Wundt expressa com clareza esta concepção

Certamente todo fenômeno psíquico é um contínuo ir e vir, um produzir e ser produzido. Nenhuma substância suprasensível, apresentada em distinção a este fenômeno, pode ajudar-nos em suas partes separadas finais, ou mesmo na conexão dessas partes dentro de uma totalidade. (...) Em parte alguma esses fatos da vida mental real precisam de qualquer substrato para sua interpretação, além do que é dado pelos próprios fatos. E a unidade dessa vida não é encontrada ao final se nós acrescentarmos à sua própria união real qualquer substância. (p. 193)

Desta forma, Wundt contrapõe-se tanto a um dualismo entre mente e corpo, quanto a um reducionismo, eliminando a idéia de uma mente substancial em prol de uma definição que a entende como uma existência ativa e em constante desenvolvimento (1896, p. 454).

A relação entre a experiência interna, pautada pelo princípio de atualidade da mente, e a externa, organizada de acordo com os princípios das leis físicas, nos leva a outro conceito central na psicologia de Wundt, o de causalidade psíquica. Para Wundt, afirmar uma causalidade própria da vida mental não contradiz sua visão monista do ser humano, uma vez que as leis psíquicas e as físicas não poderiam admitir contradição ou concorrência. Ao contrário, a causalidade psíquica deveria referir-se a valores qualitativos e às regularidades da experiência interna, enquanto as leis físicas estariam relacionadas aos valores quantitativos, adequados ao estudo dos fenômenos do tipo objeto, ambos complementando-se na explicação da experiência humana. 
Outro conceito central no pensamento de Wundt diz respeito ao postulado do paralelismo psicofísico, que sustenta essa compreensão unitária das experiências subjetiva e objetiva. Sua formulação substitui o paralelismo metafísico ao conceber que não se trata de uma correspondência contínua entre substâncias físicas e psíquicas, mas sim de uma correlação (Wechselbeziehung) ou correspondência (Korrespondenz) entre diferentes aspectos de um fenômeno unitário. Para Wundt, trata-se de um paralelismo entre conteúdos psíquicos elementares e processos físicos complexos, e não entre processos psíquicos e físicos de caráter complexo ou mesmo de elementos físicos e psíquicos (1912, p. 184-187). Dada a precedência da vida orgânica sobre os fenômenos mentais, Wundt entende que não poderia haver fenômenos psíquicos independentes de uma base física, por outro lado, isso não significaria dizer que toda complexidade da série psíquica poderia encontrar um correspondente na série física, o que significaria reduzir os fenômenos psíquicos superiores, tais como aqueles de caráter coletivo e cultural, a elementos fisiológicos.

A proposta do paralelismo psicofísico, assentada na relação intrínseca entre a experiência mediata e imediata, assumiria, portanto, um caráter metodológico, capaz de nortear os estudos científicos da vida psíquica individual, devendo, porém, ser complementada, do ponto de vista coletivo, pela observação comparada dos fenômenos complexos.

Ao tratar cientificamente a vida psíquica como uma série contínua de processos relacionados à vida orgânica, o estudo da consciência deveria acompanhar a metodologia comum às ciências naturais: 0 experimento. Wundt reconhece, contudo, que os fenômenos psíquicos não se submetem à observação da mesma forma que os objetos das ciências da natureza, mas defende que o recurso ao método experimental seria capaz de tornar a apreensão subjetiva dos processos psíquicos aproximada da observação científica. Enquanto a percepção subjetiva envolveria a apreensão casual dos fenômenos psíquicos após sua ocorrência, o método da auto-observação experimental proposto por Wundt tem como objetivo a reprodução experimental desses processos inicialmente percebidos ao acaso, modificando-os sistematicamente de forma a substituir suas condições de aparecimento e poder, então, monitorá-los antes que apareçam, conhecendo as variáveis que os influenciam e suas regras de organização (ARAUJ O, 2010, p. 168-170; WUNDT, 1896, p. 13). Com essa observação experimental exercida sobre os fenômenos da percepção casual, a psicologia alcançaria um nível de equivalência em relação ao conhecimento produzido pelas ciências naturais.

Outro aspecto que justificaria sua proposta metodológica diz respeito à noção de experiência unitária que fundamenta suas idéias. Wundt defende que, embora o método experimental só ofereça acesso 
indireto à experiência interna, estando limitado à manipulação e ao controle de suas condições externas, a confiabilidade de seu uso estaria assegurada em função de os processos psíquicos constituírem, com o mundo externo que os cerca, uma única realidade e, portanto, apresentarem-se ao estudo científico em estreita relação.

Na psicologia somente os fenômenos mentais que são diretamente acessíveis às influências físicas podem ser tomados como objetos de experimento. Nós não podemos aplicar o experimento sobre a mente propriamente, mas somente sobre suas atividades externas, os órgãos dos sentidos e movimentos que são funcionalmente relacionados aos processos mentais. (WUNDT, 1896, p. 10)

[...] sempre que possível, devemos empreender um controle sobre nossos processos mentais por meio da estimulação objetiva dos órgãos externos [...] de forma que as influências perturbadoras que as condições de observação tendem a exercer sobre eles sejam neutralizadas. Esse controle é dado pelo experimento, que não somente é capaz de produzir um fenômeno e regular suas condições conforme nossos interesses, mas é também o único recurso na psicologia capaz de traduzir a auto-observação possível durante o curso de um processo mental (WUNDT, 1896, p. 13).

Com isso, os fenômenos complexos e de caráter coletivo ficariam a cargo dos estudos comparados da Volkerpsychologie ou psicologia dos povos.

Após a apresentação destes conceitos circundantes à noção wundtiana de consciência, chegamos ao ponto em que o conceito de experiência imediata faz-nos aproximar do foco de nosso estudo. Ao se organizar como a totalidade da experiência do sujeito em seu caráter imediato, a constituição da experiência interna passará a designar simultaneamente os limites do conceito de consciência.

\section{O conceito de consciência}

Definida como ciência da experiência imediata, a psicologia científica de Wundt adotará como objeto a consciência, isto é, o recorte temporal dos processos psíquicos interconectados, constituintes da totalidade da vida mental. Em sua obra Lectures on Human and Animal Psychology (1896), ele a define como um termo útil à moderna psicologia para nomear o fato de percebermos em nós próprios representações, sentimentos e impulsos voluntários (p. 237238), não se referindo, portanto, a nenhuma fase ou aspecto particular da vida mental a ser acrescido a esses processos (1896, p. 236-238; 1897, p. 203). Conforme afirma Wundt (1896)

(...) devemos pensar o escopo da consciência como denotando simplesmente a soma dos processos mentais 
existindo em um dado momento. (...) Ela não tem nenhum sentido além desta referência à interconexão de processos mentais simultâneos e sucessivos. O problema da consciência consiste na determinação de como os fenômenos particulares são inter-relacionados e como suas relações e conexões são novamente combinadas na totalidade da vida mental. (p. 238)

Partindo inicialmente do estudo do aspecto representacional da consciência, para posteriormente complementá-lo com os aspectos afetivo e volitivo, Wundt constata que a apreensão dos processos psíquicos se dá em uma gradação, conforme níveis de clareza e distinção. Preservando a denominação da tradição leibniziana, Wundt chamará de apercepção a apreensão de extrema clareza e distinção representacional, desencadeada na presença dos processos subjetivos da atenção, enquanto se valerá da expressão percepção para referir-se ao extremo de obscuridade e indistinção. Wundt afirma não se tratar da demarcação de uma transição abrupta de uma para outra, mas sempre de uma passagem de um nível de quase total obscuridade, no qual se reconhece somente a natureza da percepção (se auditiva, visual, etc.), a níveis de maior clareza. Desta gradação decorre a utilidade da analogia com o sistema visual, segundo a qual a percepção equivaleria ao campo visual e a apercepção ao ponto focal (1896, p. 244).

Conforme a natureza de toda experiência humana, as apercepções envolveriam condições objetivas e subjetivas. As primeiras seriam encontradas nas mudanças objetivas do conteúdo representacional e constituiriam, num sentido mais estrito, a apercepção em si. Já as segundas compreenderiam as sensações subjetivas e os sentimentos, que precedem e acompanham as apercepções.

Após a recepção dos estímulos e da formulação de representações, a consciência passaria a operar com a conexão dos processos psíquicos, obedecendo à lei de causalidade psíquica. Assim, para avançarmos no estudo dos processos que constituem a consciência, seguiremos o caminho indicado por Wundt ao reconhecer que o caráter composto da experiência imediata impõe à psicologia alguns problemas, sendo o primeiro deles a análise do processo composto.

\subsection{Processos psíquicos elementares: sensações e sentimentos simples}

Admitindo que as sensações, sentimentos, representações e vontade são os indicadores a partir dos quais se reconhece a existência dos fenômenos mentais, Wundt afirma que o método natural para a investigação psicológica deve ser aquele que começa justamente por estes fatos (1896, p. 9). Partindo, portanto, da investigação experimental dos fenômenos simples da consciência, a experiência imediata poderia ser estudada em seus conteúdos objetivos 
(sensações) e subjetivos (sentimentos simples) (1897, p. 28-29).

Wundt reconhece que o caráter composto da experiência psíquica torna a simplicidade e a irredutibilidade absolutas inacessíveis à experiência humana. Não obstante, a abstração analítica em face das relações que tais elementos estabelecem entre si nos permitiria identificar os componentes psíquicos mais constantes da experiência humana e considerados como elementares, assim como seus atributos principais.

As sensações são consideradas, portanto, os processos psíquicos básicos que apresentam certa dependência em relação aos processos físicos, acompanhando os estímulos que atuam sobre os sentidos e caracterizando assim uma relação imediata com os objetos externos. Em função disso, seriam discrimináveis, isto é, as sensações características de um determinado sentido não se confundiriam com as sensações relacionadas a outros sentidos. Elas possuiriam como atributos distintivos a intensidade e a qualidade, que poderiam ser eventualmente acompanhados por descritores como clareza e obscuridade, distinção e indistinção (WUNDT, 1987, p. 31-33). Sua intensidade varia em graus, conhecendo acréscimos e decréscimos, enquanto sua qualidade varia de maneira unidirecional, isto é, indo do ponto mínimo ao ponto máximo sem transformar-se em outra sensação. As chamadas sensações simples seriam, portanto, aquelas sensações particulares encontradas quando negligenciamos temporariamente suas conexões com outras sensações, tais como uma sensação de calor, frio ou de visão (WUNDT, 1896, p. 210-211). Em relação aos sentimentos simples, Wundt os classifica como processos básicos de natureza estritamente psíquica, sem relação de dependência dos objetos externos. São, portanto, os fenômenos correspondentes às sensações quando se tem em consideração somente a experiência subjetiva. Distintamente do que ocorre com as sensações, sua relação é imediata com o sujeito, e não com os objetos, e seus atributos qualitativos variam entre extremos, passando gradualmente de uma qualidade para outra oposta, e não entre máximo e mínino de um mesmo atributo. Identificados como os elementos mais variáveis de nossa experiência imediata e sujeitos também aos atributos de clareza/obscuridade e distinção/indistinção, os sentimentos simples poderiam acompanhar as sensações, as representações compostas e os processos representacionais complexos.

De acordo com Wundt (1897, p. 29), na inter-relação de sensações e sentimentos simples, os elementos sensoriais apareceriam como mais constantes e, em função de sua referência aos objetos externos, poderiam ser isolados através da abstração, o que justificaria o início da investigação acerca dos atributos de ambos a partir das sensações. Os conteúdos da experiência psíquica consistiriam, desta forma, na combinação de vários desses elementos afetivos e 
sensitivos, de forma que seu caráter específico dependeria, em sua maior parte, não da natureza desses elementos, mas principalmente da sua união dentro de compostos psíquicos.

\subsection{Os compostos psíquicos: representações, processos afetivos e processos volitivos}

Resultantes de combinações de elementos sensoriais e afetivos, Wundt nos apresenta três categorias de compostos psíquicos: as representações, os processos afetivos e, intimamente relacionado com estes, os processos volitivos. A classe das representações seria constituída pelas imagens dos objetos externos ou das abstrações de suas noções lógicas. Como um processo composto, seria formada por sensações simples, cuja origem dependeria da excitação direta dos órgãos dos sentidos, das memórias destas impressões sensoriais e das imagens da imaginação (1896, p. 14). Por outro lado, os processos afetivos, em função da natureza simples e indecomponível dos sentimentos e de seu caráter subjetivo, não se submeteriam a semelhante análise em elementos constituintes. Em tais processos, somente seria possível observar a combinação de sentimentos simultâneos em um sentimento total que, apesar de seu caráter unitário, não equivaleria à soma dos sentimentos particulares, mas a um novo componente afetivo, qualitativamente distinto dos seus constituintes (1896, p. 218-220).

A partir destas características, a categoria das representações incluiria as representações intensivas e extensivas (espaciais e temporais), e a dos processos afetivos abarcaria as emoções, os processos volitivos e as combinações afetivas intensivas (WUNDT, 1897, p. 92-93).

As representações intensivas seriam aquelas resultantes da associação de elementos sensoriais nas quais a ordem destes elementos poderia ser variada indefinidamente, ou seja, na combinação de sensações, cada elemento seria conectado com um segundo elemento, exatamente da mesma maneira como com qualquer outro em combinações parciais equivalentes. Entretanto, tais representações possuiriam uma relação determinada e não variável com o sujeito que as produz. Um exemplo deste tipo de representação intensiva seria aquele oriundo das percepções auditivas (WUNDT, 1897, p. 93).

Também chamadas de extensivas, as representações espaciais e temporais seriam caracterizadas pelo fato de seus elementos estarem unidos numa ordem definidamente fixada em relação uns aos outros, mas não em relação ao sujeito. Neste caso, para Wundt, a relação poderia ser pensada como indefinidamente variável e capaz de explicar, por exemplo, a origem da percepção tridimensional através da independência objetiva e da capacidade de mobilidade das representações espaciais em relação ao sujeito (1897, p. 102-103). 
Em relação às representações temporais, elas apresentariam bases psicológicas mais gerais em sua constituição, não determinadas pelas estruturas particulares dos órgãos dos sentidos. Assim como as representações espaciais, elas apresentariam uma ordem definida e inalterável entre seus elementos. Entretanto, ao contrário do que ocorreria com aquelas, essa inalterabilidade atingiria também a relação dos elementos com o sujeito, de forma que cada alteração numa representação temporal, seja em relação à combinação dos elementos ou à experiência subjetiva, significaria uma nova representação.

Já o aspecto afetivo da consciência compreenderia três níveis de complexidade, cada um deles englobando distintas formas de organização e obedecendo a um princípio de unidade dos estados afetivos. Como afirma Wundt (1897)

\begin{abstract}
Ele [este princípio - acréscimo nosso] pode ser assim formulado: em um dado momento somente um sentimento total é possível, ou, em outras palavras, todo sentimento parcial presente em um dado momento forma, em cada caso, um sentimento total singular. Esse princípio de unidade dos estados afetivos está obviamente ligado à relação geral entre representação e sentimento. Pois a 'representação' refere-se a um conteúdo imediato da experiência e as propriedades que o acompanham, sem considerar o sujeito; o 'sentimento' expressa a relação que invariavelmente existe entre esse conteúdo e o sujeito. (p. 168)
\end{abstract}

No nível mais simples dos processos afetivos estariam os chamados sentimentos compostos - estados intensivos de caráter unitário, constituídos pelas combinações de sentimentos parciais, presentes na consciência em dado momento, e sua síntese em um sentimento total. São também chamados de combinações afetivas intensivas, uma vez que sua origem está relacionada às relações qualitativas entre os atributos sensoriais das representações, enquanto as combinações extensivas estariam ligadas à organização espacial e temporal das mesmas. A forma mais simples destes sentimentos compostos encontrar-se-ia intimamente ligada às condições sensoriais e sua forma mais elaborada associada a complexos representacionais.

O nível seguinte de complexidade seria formado pelas emoções, que representariam uma sucessão unitária de sentimentos, distinguível de processos antecedentes e subseqüentes como uma totalidade individual, cujo efeito no sujeito seria mais intenso do que o causado pelos sentimentos singulares. Não se trataria, portanto, de qualquer conteúdo subjetivo específico da experiência, distinto dos sentimentos, mas sim de um efeito oriundo de uma combinação especial destes mesmos sentimentos. São, desta forma, nas palavras 
de Wundt (1896), processos afetivos de um estágio superior aos sentimentos, e constituiriam um dos fenômenos mentais mais importantes, capaz de exercer influência sobre os processos representacionais e sobre as ações voluntárias. Ligadas às conexões representacionais na consciência, as emoções difeririam dos sentimentos somente pelo fato de encontrarem uma expressão externa através das reações dos órgãos dos movimentos e pela alteração causada na cadeia de representações. Para Wundt, o processo da emoção envolveria três estágios: o surgimento de um sentimento inicial; a mudança subseqüente causada nas representações conectadas, intensificando e modificando qualitativamente esse sentimento inicial; e, por fim, a ocorrência de um sentimento final, de maior ou menor duração, que tende a desaparecer gradativamente, podendo, antes disso, dar origem a uma nova emoção, na qual cumpriria, então, o papel de um sentimento inicial. Essa alteração promovida na representação daria origem a duas classes de emoções: as excitatórias e as inibitórias ( $p$. 372).

Além da associação com os elementos sensoriais e com as representações, a emoção estaria relacionada com o processo da memória, de forma que a excitação daquela só poderia se dar mediante uma espécie de reconhecimento da representação sensorial. Como diz Wundt (1896), "onde uma emoção aparece, pode-se supor a presença de representações mnêmicas de experiências nas quais uma impressão sensorial similar foi, de certo modo, a causa" ( $p .375$ ).

As emoções também acompanhariam certos processos intelectuais, dando origem aos chamados sentimentos intelectuais: os sentimentos lógicos, éticos, religiosos e estéticos, que deveriam ser estudados pelas áreas particulares correspondentes. Configurando-se como expressões superiores da consciência humana, eles se apresentariam ligados a conexões representacionais muito complexas e seriam capazes de exercer uma influência sobre a vida mental superior à de qualquer outro processo afetivo (WUNDT, 1896, p. 378).

Todavia, uma emoção ainda poderia ser interrompida de maneira súbita, ao invés de desaparecer gradativamente. Tal desdobramento ocorreria em função de uma mudança na sucessão de representações, capaz de levar a uma alteração brusca nos conteúdos afetivos e sensoriais. Esta mudança no estado afetivo e sensorial Wundt chama de ato volitivo, e a própria emoção acompanhada deste resultado, de processo volitivo. Tais processos estariam relacionados com a emoção sob a forma de um fenômeno de estágio superior, do mesmo modo que uma emoção estaria relacionada a um sentimento (1897, p. 172). Compondo uma seqüência contínua de desenvolvimento, o estágio inferior dos processos volitivos seria 
representado pelos atos voluntários simples ou expressões do impulso, e os estágios superiores, os atos de escolha, compreendidos como aqueles próprios da atividade volitiva (1896, p. 423). Para Wundt, este seria o aspecto característico da singularidade da experiência humana em relação ao reino animal, uma vez que o problema da volição estaria inescapavelmente associado à questão da causalidade e da liberdade (1896, p. 423-424).

\title{
2.3. Os processos de composição e as leis da vida psíquica
}

Respeitando sua concepção monista acerca da experiência e procurando preservar a singularidade e irredutibilidade da perspectiva subjetiva, Wundt considera, em An Introduction to Psychology (1912), que também a noção de lei deve ser coerente com a natureza dos objetos a que se pretende aplicar. Desta forma, a regularidade observada nos fenômenos psíquicos deveria estar sujeita a leis próprias, as chamadas leis psíquicas. Sua distinção em relação às leis físicas seria devida à natureza processual e intangível dos seus objetos, enquanto estas últimas poderiam contar com uma regularidade espaço-temporal mais estável. Para Wundt, tais leis sustentar-se-iam nos seguintes termos:

\begin{abstract}
Nós mantemos como um princípio para as leis psíquicas que tanto os componentes quanto os resultantes dos efeitos de tais leis sejam partes da consciência imediata, isto é, sensações, sentimentos e suas combinações. Se lançarmos um olhar, mantendo-nos firmes a este critério, sobre os diversos processos da consciência, [...] vemos imediatamente que todos esses processos apresentam um caráter de estrita regularidade. Não no sentido de que tais leis são regras fixas sem exceções [...], mas no único sentido permissível, isto é, de que tais fenômenos complexos podem ser reduzidos a uma cooperação entre elementos regida por leis. Se essa exigência não fosse atendida, não poderia haver coesão em nossa vida psíquica (WUNDT, 1912, p. 158)
\end{abstract}

A menção a elementos não deve, entretanto, ser confundida com uma hipótese metafísica sobre a existência de estruturas simples, tal como átomos mentais, nem com uma ênfase nos elementos estruturais que viria a ser defendida mais tarde por Titchener, como consta em alguns manuais (MARX; HILLIX, 1995), mas sim como uma necessidade metodológica coerente com o princípio do paralelismo psicofísico, que estabelece o ponto de partida dos estudos da vida mental nos processos mais simples, diretamente associados às condições físicas.

A partir da observação dos constituintes simples dos processos psíquicos e de suas combinações em formas mais complexas, Wundt (1897) propõe que a regulação da vida mental envolveria duas classes de leis, às quais chamou de leis de relação e de 
desenvolvimento dos processos psíquicos. As leis de relação diriam respeito às condições para o surgimento e interação imediata dos compostos psíquicos e compreenderiam a lei dos resultantes, das relações e dos contrastes psíquicos. Já a classe das leis de desenvolvimento derivaria da primeira e consistiria nos efeitos complexos produzidos por combinações de leis de relação com séries mais extensas de fatos psíquicos. Elas compreenderiam as leis do crescimento mental, da heterogonia dos fins e da intensificação por contrastes (p. 325-326).

Em seu Outlines of Psychology (1897), Wundt apresenta a lei dos resultantes psíquicos como relacionada ao caráter sintético e produtivo das interações de compostos psíquicos e reconhecida mais claramente nas funções aperceptivas e nas atividades da imaginação e do entendimento. Ela afirma que "cada composto apresenta atributos que podem ser entendidos a partir dos atributos dos seus elementos, embora de modo algum eles devam ser vistos como a mera soma destes atributos" (p. 321). Tal lei expressaria o chamado princípio da síntese criadora, segundo o qual as combinações psíquicas conteriam sempre algo qualitativamente distinto de seus componentes, não obedecendo à equivalência entre causa e efeito, decorrente do princípio de conservação de energia, e atribuindo à explicação psicológica um caráter regressivo, isto é, somente possível posteriormente à ocorrência dos fenômenos, e não a partir da simples observação dos elementos constitutivos.

Já a lei das relações psíquicas, embora complementar à primeira, obedece ao princípio de que os elementos psíquicos estabelecem relações entre si, a partir das quais o produto necessariamente surge e se podem afirmar as condições de fundamento e conseqüência desempenhada por cada elemento. Nas palavras de Wundt (1897, p. 324), “(...) o conteúdo essencial da lei de relação é o princípio de que cada conteúdo psíquico singular recebe seu significado a partir das relações que ele mantém com outros conteúdos psíquicos". Por sua vez, a lei do contraste psíquico expressa o fato de que, ao longo do desenvolvimento psíquico, os conteúdos da experiência subjetiva são intensificados a partir de relações de oposição, apresentando, segundo Wundt (1897), uma singularidade em relação às demais:

\footnotetext{
A lei do contraste está intimamente relacionada com as duas leis precedentes. Por um lado, ela pode ser vista como a aplicação da lei geral das relações ao caso especial em que os conteúdos psíquicos estão situam-se entre limites opostos. Por outro lado, o fato de que, sob circunstâncias adequadas, processos psíquicos antitéticos podem intensificar-se mutuamente, mantendo-se sob a lei dos contrastes, é ao mesmo tempo uma aplicação especial do princípio da síntese criadora. (p. 325)
} 
Mediante essas leis, os compostos psíquicos citados no item anterior poderiam ser analisados em dois níveis: a partir da combinação dos elementos sensoriais e afetivos que os constituem, e a partir da interconexão destes compostos na forma de processos psíquicos superiores. Ao tratar deste primeiro nível de composição, Wundt afirma em seu Outlines (1897) que

\begin{abstract}
esses processos de combinação são dos tipos mais variados; [...] entretanto, as diferenças mais gerais entre eles são aquelas exibidas pela atenção na recepção passiva das impressões e na apercepção ativa das mesmas. Para nomear essas diferenças nós usamos os termos associação para indicar o processo de combinação em um estado passivo da atenção e combinação aperceptiva para indicar uma combinação na qual a atenção é ativa. (p. 224 - ênfase no original)
\end{abstract}

Para Wundt, a atenção não constitui uma atividade distinta dos demais elementos psíquicos, mas refere-se aos processos coordenados de sensações e sentimentos que acompanham e favorecem a apreensão clara dos conteúdos que se apresentam à consciência. Conforme dito no início do item 2, o conceito de atenção diz respeito às sensações musculares e aos sentimentos que precedem e acompanham as mudanças representacionais na apercepção, sendo, portanto, um processo complexo de caráter subjetivo. Por isso, dizemos que a presença da atenção é o que determina a entrada das representações no campo visual ou no ponto focal da consciência, distinguindo assim o processo perceptivo do aperceptivo, respectivamente.

A atenção, em sua forma passiva, diz respeito a um estado de receptividade no qual o processo atencional não é precedido por influências afetivas preparatórias, sendo acionado pela entrada brusca de um novo conteúdo no ponto focal da consciência. Este estado é o que caracteriza os processos associativos que ocorrem nas apercepções passivas. Por outro lado, a forma ativa da atenção caracteriza-se pela presença de elementos afetivos antecedentes e por sensações de tensão nos músculos dos órgãos sensoriais afetados pelo novo conteúdo. Esta condição dá origem às combinações aperceptivas, que são formas mais fortes de combinação entre os elementos. Além da referência à força das uniões, Wundt adota o termo associação para indicar combinações elementares e o termo combinação aperceptiva para aquelas uniões que dão origem a compostos psíquicos de diferentes gêneros (1897, p. 226-227). A não atenção a esta distinção é o que explica o fato de Wundt ter sido considerado um associacionista (HERRNSTEIN; BORING, 1971), quando na verdade a associação ocupava um lugar secundário na explicação da formação dos compostos, sendo a combinação 
aperceptiva a verdadeira responsável pelas composições que caracterizam a complexidade da vida psíquica.

Para Wundt, as associações apresentariam tanto um caráter simultâneo como sucessivo. Diferenciando-se em assimilações e complicações, as principais características das associações simultâneas seriam estabelecerem-se entre os elementos, e não entre a totalidade das representações, e o fato de seus componentes modificarem-se uns aos outros através de assimilações recíprocas. $\mathrm{Na}$ primeira forma de associação simultânea, a assimilação, a combinação seria de caráter pouco intenso e envolveria uma sensopercepção externamente excitada e a imagem mnêmica relacionada, geralmente uma representação espacial intensiva (1896, p. 287). Já as complicações são definidas por Wundt como sendo combinações simultâneas que envolveriam sensações e percepções de diferentes sentidos em produtos unitários como, por exemplo, um som e uma imagem, que, por serem unidos de modo mais fraco do que ocorreria nas assimilações, permitiriam que as diferenças entre seus componentes fossem preservadas (1896, p. 285; 1897, p. 234-235). Apesar deste aspecto, o caráter unitário do produto seria garantido pela predominância que um componente adquiriria sobre o outro, sobressaindo-se na consciência.

Quanto ao caráter sucessivo das associações, ele diferiria das simultâneas somente em um aspecto secundário, que diz respeito à possibilidade que suas associações teriam de serem divididas em dois atos, enquanto estas últimas consistiriam num ato singular instantâneo. Desta forma, uma vez que não haveria diferença constitutiva entre as associações simultâneas e as sucessivas, os processos representacionais ou afetivos resultantes destas últimas seriam igualmente formados através da assimilação e da complicação (WUNDT, 1897, p. 236).

Por outro lado, no estado de atenção ativa os processos de combinação são chamados por Wundt de combinações aperceptivas ou fusões e conheceriam duas funções: as funções aperceptivas simples e as complexas. As primeiras seriam funções parciais interdependentes, conhecidas como funções de relação e funções de comparação.

Para Wundt (1897, p. 250), a relação existente entre dois conteúdos psíquicos seria definida como "uma atividade aperceptiva através da qual a própria relação assume um conteúdo consciente especial, distinto dos conteúdos que são relacionados, embora na verdade seja inseparavelmente conectado com eles". Para Wundt, distintamente do sentido fisiológico, em que a soma das partes singulares equivaleria ao novo composto, no sentido psicológico a fusão indicaria a criação de novos valores não contidos nos elementos constituintes, sendo, portanto, o processo psíquico que melhor expressaria o princípio da síntese criadora. 
Em complemento a esta função aperceptiva de relação, a categoria das funções de comparação é apresentada por Wundt como constituída por duas funções elementares, intimamente conectadas: a percepção da concordância e a percepção das diferenças entre os compostos e elementos psíquicos, referindo-se à qualidade, à intensidade e aos graus de clareza destes conteúdos (1897, p. 251252).

Quando tais processos simples de relação e comparação são repetidos diversas vezes ao longo do tempo, surgem as funções aperceptivas complexas: a síntese e a análise. A síntese aperceptiva teria como base os processos de fusão e associação e seria principalmente um produto da atividade de relação da apercepção, embora se diferencie desta pelo fato de seus elementos afetivos e representacionais serem enfatizados seletiva e voluntariamente. Além destas características, a função de síntese resultaria em duas formas de atividade aperceptiva, a atividade da imaginação e a do entendimento. O processo de análise aperceptiva, por sua vez, estaria relacionado à atividade de comparação e, assim, teria como resultado a capacidade de julgamento.

\section{Autoconsciência: alteração constante e conexão contínua}

Explicados os processos que, em sua totalidade, constituem o conceito de consciência wundtiano, algumas dúvidas podem surgir, como, por exemplo, como podemos reconhecer que tais processos se refiram a nós próprios? Ou, em outras palavras, se a consciência é somente a totalidade de processos interconectados num dado período, sem qualquer referência a algo distinto, externo e organizador dos mesmos, como é possível uma consciência de si ou autoconsciência? Se, conforme afirma Wundt, um mesmo processo nunca retorna, embora seu sucessor possa lhe ser similar, e a mera similaridade não prova a continuidade da existência, como responder a esta pergunta?

Para Wundt, a explicação da noção de autoconsciência - uma espécie de aplicação especial da consciência - estaria intimamente relacionada ao conceito de atenção, de apercepção e, em última instância, ao corpo, dando origem à discriminação entre sujeito e objeto. Equivalente ao conceito de self, a autoconsciência é definida da seguinte forma por Wundt (1896):

Do ponto de vista psicológico, o self não é uma representação entre outras representações; ele não é nem mesmo uma característica secundária comum a todas ou à maioria das representações; ele é única e simplesmente a percepção da interconexão da experiência interna que acompanha essa própria experiência. (p. 250) 
O self, ou autoconsciência, é, portanto, o sujeito que atribuímos à atividade aperceptiva (WUNDT, 1896, p. 251). Para Wundt, esta idéia de atividade envolveria duas características: uma mudança nas condições de algo e um sujeito cujos estados variassem com esta mudança, de forma que ambos pudessem ser correlacionados. Sendo a atenção o processo característico da apercepção e que envolve a variação na clareza das representações, sensações musculares e sentimentos que precedem e acompanham as representações durante 0 ato aperceptivo, estaríamos inclinados a derivar a atividade aperceptiva de um sujeito autoconsciente. E, como diz Wundt (1896, p. 250), "uma vez que encontramos entre esses elementos não somente alteração constante, mas também uma conexão contínua dos processos iniciais com os últimos, nós observamos o sujeito atuante como persistindo através de todas essas mudanças".

Em função desse caráter ininterrupto das séries de desenvolvimento mental (WUNDT, 1896, p. 249), o self seria visto como o mesmo, apesar das variações, já que elas seriam sempre contínuas tanto no tempo como no espaço, através da constância de seu substrato - o corpo - e nos permitira, assim, conhecer a continuidade e a variação das coisas objetivas. A abstração que nos facultaria conceber a autoconsciência como distinta em relação aos outros conteúdos da consciência é que daria origem à discriminação da noção de sujeito e objeto, conceitos derivados da reflexão sobre as inter-relações dos vários componentes da experiência imediata unitária, e não de naturezas singulares previamente dadas (WUNDT, 1897, p. 222-223). Seria, portanto, a percepção da interconexão da própria experiência que permitiria à consciência uma compreensão unificada acerca de si mesma.

\section{Considerações Finais}

A apresentação do conceito de consciência formulado por Wundt, longe de esgotar a riqueza de sua obra, nos permite vislumbrar um projeto de psicologia que, se não encontra mais adeptos nos dias atuais, ainda não pode ser considerado obsoleto, uma vez que seu necessário debate e eventual refutação não foram, até o momento, empreendidos. Como indicado na literatura secundária, embora tenha formado alunos de diversas partes do mundo e sido traduzido para vários idiomas (WUNDT, 1927; ARAUJ O, 2009b; BRINGMANN; BRINGMANN; UNGERER, 1980; ROBINSON, 2001), as idéias de Wundt foram em parte mal compreendidas por seus alunos e acabaram desconfiguradas. Os fatores relacionados a esta má compreensão têm sido indicados pela literatura e vão desde a desconsideração da tradição filosófica que sustenta o projeto psicológico wundtiano (BLUMENTHAL, 1980; DANZIGER, 1979, $1980 a, 1980 b)$ até ao interesse estrito nos aspectos experimentais de sua psicologia (ROBINSON, 2001). Ao voltarem para seus países de 
origem, muitos de seus alunos acabaram por estabelecer novas propostas teóricas, adequadas a seus interesses e que se afastavam das idéias de Wundt. Por outro lado, como sugere Blumenthal (1980), parte da produção sobre Wundt que surgiu nas primeiras décadas do século $X X$, em língua inglesa, desencorajava o exame dos materiais originais pelos novos psicólogos. A soma de tais fatores resultou numa apresentação parcial e, por vezes, caricatural da personalidade e da obra de Wundt (cf. BORING, 1950), que formou mais de uma geração de psicólogos e pode ser sentida em muitos manuais de psicologia das décadas seguintes (BROCK, 1993; MARX; HILLIX; 1995; ZEHR, 2000).

Sua noção de experiência unitária, abordável em suas características imediata e mediata, sob a qual se assenta a possibilidade de autonomia da psicologia e de superação de um dualismo mentecorpo, é fundamental para a compreensão de seu conceito de consciência. Concebidas como séries de processos em desenvolvimento, as características imediata e mediatamente percebidas poderiam ser estudadas por meio de um paralelismo psicofísico, segundo o qual a unidade da experiência poderia ser analisada em seu aspecto psíquico ou físico, até determinados limites, dentro dos quais seria possível, quando necessário, adotar a referência a um termo de uma série em substituição ao da outra, quando fosse impossível remontar às origens da série em questão.

A experiência imediata seria o aspecto da experiência caracterizado pela referência direta ao sujeito. Seus fenômenos não possuiriam a mesma estabilidade daqueles da experiência mediata e sua natureza processual nos obrigaria a um acesso indireto a eles, por meio da observação experimental. Ainda assim, não poderíamos, segundo Wundt, falar num mapeamento completo da vida psíquica, mas tão somente no estudo dos processos percebidos clara e distintamente e em ligação direta com os órgãos dos sentidos, restando ainda aqueles percebidos parcialmente ou de forma completamente indistinta. Essa restrição, porém, não seria tão limitadora, uma vez que, com a colaboração de sua Völkerpsychologie, poderíamos ainda avançar na compreensão dos fenômenos superiores da mente humana, surgidos a partir da vida coletiva e dos contextos culturais.

Definida desta forma, a experiência imediata estabeleceria igualmente os limites de seu conceito de consciência - a totalidade dos processos psíquicos - sensações, sentimentos, representações e processos volitivos - interconectados em níveis cada vez mais complexos, num determinado momento. Sem qualquer referência a uma natureza especial, sua definição de consciência nos leva à interrogação sobre o que nos permitiria a apreensão destes processos como uma unidade auto-referida. Wundt nos apresenta, então, um segundo nível de percepção, aquele que reconhece a interconexão da própria experiência interna - a autoconsciência ou self. 
Diante da relevância e da amplitude que o conceito de consciência assume, como fundamento para as mais diversas formulações psicológicas, pretendemos, ao final deste percurso, ter apresentado de modo satisfatório e fidedigno a definição de consciência wundtiana como um exemplo de um projeto científico que, embora passível de questionamento, pretende indicar à psicologia a necessidade de retornar o olhar para uma fundamentação filosófica criteriosa de seus termos, caso queira responder aos vetos históricos que Ihe foram direcionados e dialogar com os avanços contemporâneos das neurociências.

\section{Referências Bibliográficas}

ARAUJ O, S. F. Wilhelm Wundt e o estudo da experiência interna. In: J ACÓ-VILELA, A. N.; FERREIRA, A. A. L.; PORTUGAL, F. T. (Orgs.)., História da psicologia: rumos e percursos. 2a ed. revista e ampliada. Rio de Janeiro: Nau, 2007, p. 92-104.

ARAUJO, S. F. Uma visão panorâmica da psicologia científica de Wilhelm Wundt. Scientiae studia, v. 7, n. 2, p. 209-220, abriljunho 2009a.

ARAUJO, S. F. Wilhelm Wundt e a formação do primeiro centro internacional de formação de psicólogos. Temas em psicologia, v. 17, n. 1, p. 09-14, 2009b.

ARAUJO, S. F. O projeto de uma psicologia científica em Wilhelm Wundt: uma nova interpretação. Juiz de Fora: UFJ F, 2010. BLUMENTHAL, A. L. Wilhelm Wundt - Problems of interpretation. In: BRINGMANN, W. G.; TWENEY, R. D. (Eds.)., Wundt studies: a centennial collection. Toronto: C. J. Hogrefe, 1980, p. 435-445.

BLUMENTHAL, A. L. A Wundt primer: the operating characteristics of consciousness. In: RIEBER, R. W. \& ROBINSON, D. K. (Eds.). Wilhelm Wundt in history: the making of a Scientific Psychology. New York: Klumer Academic/Plenum Publishers, 2001, p. 121-144.

BORING, E. G. A history of experimental psychology. $2^{\text {nd }} \mathrm{Ed}$. New York: Appleton-Century-Crofts, Inc., 1950, p. 316-347.

BRINGMANN, W. G.; BRINGMANN, J. N.; UNGERER, G. A. The Establishment of Wundt's Laboratory: An Archival and Documentary Study. In: BRINGMANN, W. G.; TWENEY, R. D. (Eds.)., Wundt studies: a centennial collection. Toronto: C. J. Hogrefe, 1980, p. 123-157.

BROCK, A. Something old, something new: The 'reappraisal' of Wilhelm Wundt in textbooks. Theory \& Psychology, v. 3, n. 2, p. 235-242, 1993.

BROZEK, J. The echoes of Wundt's work in the United States, 18871977: A quantitative citation analysis. In: BRINGMANN, W. G. \& SCHEERER, E. (Eds.). Psychological research. Wundt centennial issue. v. 42, n. 1-2, p. 103-107, 1980. 
DANZIGER, K. The positivist repudiation of Wundt. Journal of the History of the Behavioral Sciences, v. 15, p. 205-230, 1979.

DANZIGER, D. Wundt and the two traditions of psychology. In: Rieber, R. W. (Ed.)., Wilhelm Wundt and the making of a scientific psychology. New York / London: Plenum Press, p. 73-87, 1980a.

DANZIGER, K. Wundt's psychological experiment in the light of his philosophy of science. Psychological Research. Wundt Centennial Issue, v. 42, n. 1-2, p. 109-122, 1980 b.

FERRARI, M.; ROBINSON, D. K.; YASNITSKY, A. Wundt, Vygotsky and Bandura: A cultural-historical science of consciousness in three acts. History of the human sciences, v. 23, n. 3, p. 95-118, 2010. HERRNSTEI N, R. J.; BORING, E. G. Textos básicos de história da psicologia. São Paulo: Herder/Universidade de São Paulo, 1971.

$\mathrm{KOCH}, \mathrm{S}$.; LEARY, D. E. A century of pychology as Science. Washington, D.C.: American Psychological Association, 1992.

MARX, M.; HILLIX, W. Sistemas e teorias em psicologia. São Paulo: Cultrix, 1995.

RAPPARD. H. V. A monistic interpretation of Wundt's Psychology. In: BRINGMANN, W. G.; SCHEERER, E. (Eds.). Psychological Research. Wundt centennial issue, v. 42, n. 1-2, p. 123-134, 1980. RIEBER, R. W. Wundt and the Americans - From flirtation to abandonment. In: RIEBER, R. W.; ROBINSON, D. K. (Eds.). Wilhelm Wundt in history: the making of a scientific psychology. New York: Klumer Academic/Plenum Publishers, 2001, p. 145-160. ROBINSON, D. K. Reaction-time experiments in Wundt's institute and beyond. In: RIEBER, R. W.; ROBINSON, D. K. (Eds.)., Wilhelm Wundt in History: The making of a scientific psychology. New York: Kluwer Academic / Plenum Publishers, 2001, p. 161-204.

STURM, T.; WUNDERLICH, F. Kant and the scientific study of consciousness. History of the human sciences, v. 23, n. 3, p. 4871, 2010.

TAIANA, C. Conceptual resistance in the disciplines of the mind: The Leipzig-Buenos Aires connection at the beginning of the $20^{\text {th }}$ century. History of psychology, v. 8, n. 4, p. 383-402, Novembro, 2005. TINKER, M. A. Wundt's Doctorate Students and Their Theses 18751920. In: BRINGMANN, W. G.; TWENEY, R. D. (Eds.). Wundt Studies - A Centennial Collection. Toronto: C. J. Hogrefe, 1980, p. 269-279.

WUNDT, E. Wilhelm Wundts Werk. Ein Verzeichnis seiner sämtlichen Schriften. München: Beck, 1927.

WUNDT, W. Lectures on human and animal psychology. $2^{\text {nd }}$ ed. London: Swan Sonnenschein \& Co.; New York: Macmillan \& Co., 1896 (Obra original publicada em 1863).

WUNDT, W. Outlines of psychology. $2^{\text {nd }}$ ed. Translated by Charles Hubbard Judd. Toronto: York University, 1897 (Obra original 
publicada em 1896).

WUNDT, W. An introduction to psychology. $2^{\text {nd }}$ ed. Translated by Rudolf Pinter. London: George Allen \& Unwin, 1912 (Obra original publicada em 1911).

WUNDT, W. Sistema de filosofía científica ó sea fundamentos de metafísica basada em las ciencias positivas. 3ạ ed. Traducida por Eloy Luis André. Madrid: Daniel Jorro, 1913. (Obra original publicada em 1889).

WUNDT, W. A missão da filosofia na actualidade. Traduzida por Mario Basto Wagner e Carlos Pessanha Pereira. Lisboa: Tipografia Henrique Torres, 1920.

ZEHR, D. Portrayals of Wundt and Titchener in introductory psychology texts: A content analysis. Teaching of Psychology, v. 27, n. 2, p. 122-127, 2000.

\section{Endereço para correspondência:}

Cíntia Fernandes Marcellos

Universidade Federal de J uiz de Fora, Instituto de Ciências Humanas/Departamento de Psicologia, Rua José Lourenço Kelmer, s/n - Campus Universitário, Bairro São Pedro, CEP 36036-900, Juiz de Fora - MG, Brasil

Endereço eletrônico: cintia.marcellos@gmail.com

Saulo de Freitas Araujo

Universidade Federal de Juiz de Fora, Instituto de Ciências Humanas/Departamento de Psicologia, Rua José Lourenço Kelmer, s/n - Campus Universitário, Bairro São Pedro, CEP 36036-900, Juiz de Fora - MG, Brasil

Endereço eletrônico: saulo.araujo@ufjf.edu.br

Recebido em: 03/09/2010

Aceito para publicação em: 22/09/2010

Acompanhamento do processo editorial: Ana Maria Jacó-Vilela

\section{Notas}

* Mestranda da Universidade Federal de Juiz de Fora - UFJF

** Professor Doutor do Departamento de Psicologia e do Programa de Pós-

Graduação em Psicologia da Universidade Federal de Juiz de Fora - UFJF. 